\title{
Application of calorimetry as a main tool in evaluation of the effect of carbonate additives on cement hydration
}

\author{
W. Nocuń-Wczelik $\cdot$ B. Trybalska $\cdot$ E. Żugaj
}

Received: 19 October 2012/ Accepted: 16 January 2013/Published online: 12 February 2013

(C) The Author(s) 2013. This article is published with open access at Springerlink.com

\begin{abstract}
Calorimetry was applied to follow the hydration in the Portland cement-dolomite-limestone mixtures. In the experiments the limestone additive of various fineness (standard component of various common cements), as well as the dolomite additive (not a standard component) were used. The rate of hydration versus time for common cements reflects the proper setting and early hardening during the first days after mixing with water (two or three peaks and the induction period between them). The aim of measurements presented in this work was to show the course of heat evolution curve and the heat evolved values, equivalent to the acceleration/retardation of hydration, in case of the pastes produced from Portland cement and the carbonate additives mixed in variable proportions, as well as to verify the results by other methods. The rate of heat evolution accompanying cement paste hydration, total heat evolved, conductivity of hydrating suspension and rheological (flow) properties versus time are modified by the fine grained carbonate additives. This is due to the hypothetical nucleating effect of limestone and dolomite.
\end{abstract}

Keywords Cement - Limestone - Dolomite ·

Heat of hydration $\cdot$ Rheology $\cdot$ Chemical shrinkage

\section{Introduction}

The kinetics and mechanism of hydration in various cementitious systems can be investigated by calorimetry

W. Nocuń-Wczelik $(\bowtie) \cdot$ B. Trybalska · E. Żugaj Faculty of Material Science and Ceramics, University of Science and Technology AGH, Al. Mickiewicza 30,

30-059 Kraków, Poland

e-mail: wiesia@agh.edu.pl
[1-4]. The heat evolution curve $(\mathrm{d} Q / \mathrm{d} t=f(t))$ reflects the fluctuations of the overall rate of reactions occurring in the hydrating system and accompanying cement setting and hardening. The heat evolution profile consists generally of the two peaks with the induction period between them and this can be observed only in case of binding materials in which the hydration reactions, structure formation and, finally, proper setting and strength development takes place. The heat evolved versus time plot corresponds to the growth of hydration products.

The production of Portland cement containing limestone, interground or blended with clinker, has increased in the past decades due to technical, economical and environmental reasons [5-7]. The technical reasons mean the satisfactory physical and mechanical properties of hydrated cement paste; the economic and environmental reasons include energy saving during the decreased clinker production and consequently the reduction of environmental pollution by carbon dioxide.

The idea of using dolomite as a component of cement is not quite new. Some reports appeared in early 80-ties in Germany [8, 9]. However, this material has not been taken into account in the European standardization process, when the Portland limestone cement was implemented. Theoretically, in highly alkaline environment of cement paste the so-called dedolomitization process can occur, leading to the formation of brucite with no binding properties and possible risk of damage due to expansion. There are the other phenomena discussed as the alkali carbonate reaction in the paste (dolomite) aggregate interface is concerned [10, 11].

In some countries the limestone deposits do not comply with the quality requirements given in the EN 197-1 standard (min. $75 \% \mathrm{CaCO}_{3}$ ) because they contain inclusions of dolomite and their more economical disposal is required. Only a few reports dealing with dolomite usage as cement 
constituent have appeared and according to all authors dolomite can be implemented as cement component; quite recently in Germany there was a research project $[8,9]$.

The usage of dolomite/dolomitized limestone is expected to increase in the nearest future in terms of the growth of supplementary cementing materials ratio in cements, forced by reduction of carbon dioxide emission. The possible application of dolomitized limestone as a component of mixtures for geotechnical application should be considered. This problem can be related generally to the idea of sustainable development.

This study focused on the kinetics of early hydration in the Portland cement-dolomite-limestone mixtures. The following techniques, providing the continuous monitoring of hydration process were used: calorimetric measurements, electric conductivity measurements in the hydrating suspensions, shrinkage and rheological characteristics of hydrating cement pastes.

\section{Experimental}

\section{Materials}

The commercially produced standard Portland cements CEM I $42,5 \mathrm{R}$ was used (Blaine specific surface $3,550 \mathrm{~cm}^{2} \mathrm{~g}^{-1}$ ). The chemical composition of cement is given in Table 1 . The following carbonate additives were used:

Fine limestone powder; $\mathrm{CaCO}_{3}-$ min. $99.0 \%$ (Blaine specific surface $14,500 \mathrm{~cm}^{2} \mathrm{~g}^{-1}$ ).

Coarse limestone powder; $\mathrm{CaCO}_{3}-\min .98 .5 \%$ (Blaine specific surface $1,500 \mathrm{~cm}^{2} \mathrm{~g}^{-1}$ ).

Dolomite; $\mathrm{CaCO}_{3} \cdot \mathrm{MgCO}_{3}$-min. $98.0 \%$ (Blaine specific surface $4,600 \mathrm{~cm}^{2} \mathrm{~g}^{-1}$ ).

The grain size distribution of particular carbonate reagents is plotted in Fig. 1.

The mixtures of cement with limestone of different fineness and the mixtures of cement with dolomite were subsequently produced.

As one can see the grain size distribution curves of basic cement and dolomite run close to each other (Fig. 1).

\section{Methods}

The rate of heat evolution was followed by means of differential microcalorimeter on the pastes at water to cement ratio 0.5 . The measurements of conductivity were carried

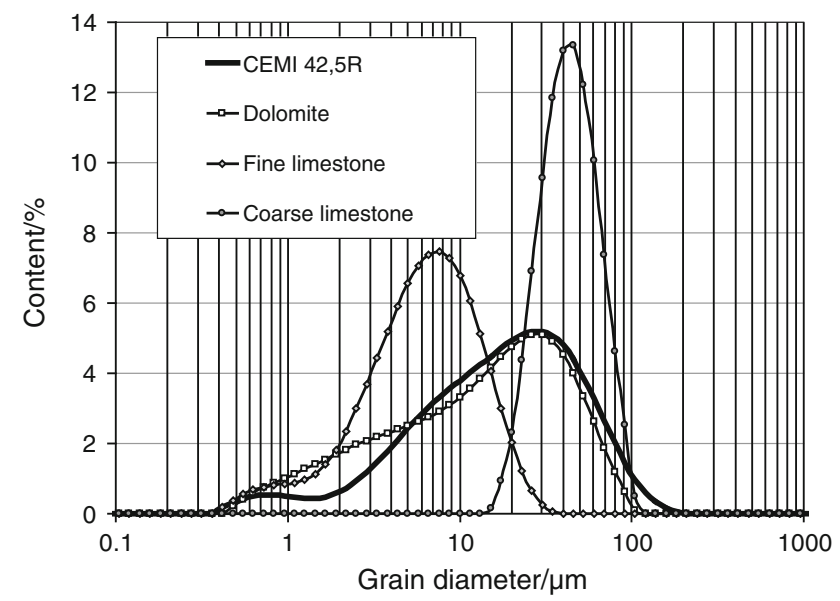

Fig. 1 Grain size distribution of cement and particular carbonate reagents

out on the continuously stirred water-cement suspensions at $w / c=10$, with help of equipment with sensor and measuring device. The measurements were carried out at temperature $20{ }^{\circ} \mathrm{C}$ in glove box using calibrated $\mathrm{Hg}$ electrode. The rheological parameters of hydrating suspensions were determined from the flow curves taken with a rotational viscometer. Some selected samples were subjected to the evaluation of the so-called chemical shrinkage, using basic laboratory equipment (glass vials and pipettes) and procedure similar to that given in the ASTM Standard C 1608-07 [12, 13]. Some samples were observed under SEM with EDS microanalyzer, to characterize the microstructure.

\section{Results and discussion}

The heat evolution curves are shown in Figs. 2, 3, 4. In Table 2 some parameters relating to the heat evolution curves characteristics are listed. The changes of conductivity versus time for cement-water suspensions with admixtures are plotted in Fig. 5; the results of chemical shrinkage in Fig. 6 and the flow curves in Fig. 7, respectively. The example microstructures of fractured 7-day hydrated samples are presented in Fig. 8.

From the data presented above one can see that the additives do not reduce markedly the rate of heat evolution or the total heat evolution as it would result from their percentage in the hydrated mixtures. Added as $5 \%$ by mass of mixed binder they play a role of active cement replacement and this refers both to the fine, coarse limestone and dolomite powder. Obviously, the effect of the

Table 1 Chemical composition of cement

\begin{tabular}{llllllllllll}
\hline Components & $\mathrm{SiO}_{2}$ & $\mathrm{Al}_{2} \mathrm{O}_{3}$ & $\mathrm{Fe}_{2} \mathrm{O}_{3}$ & $\mathrm{CaO}$ & $\mathrm{MgO}$ & $\mathrm{SO}_{3}$ & $\mathrm{Na}_{2} \mathrm{O}$ & $\mathrm{K}_{2} \mathrm{O}$ & $\mathrm{Cl}^{-}$ & $\mathrm{Loi}^{-}$ \\
\hline Percentage & 20.2 & 5.7 & 3.2 & 64.5 & 1.6 & 2.1 & 0.18 & 1.11 & 0.013 & 1.4 \\
\hline
\end{tabular}




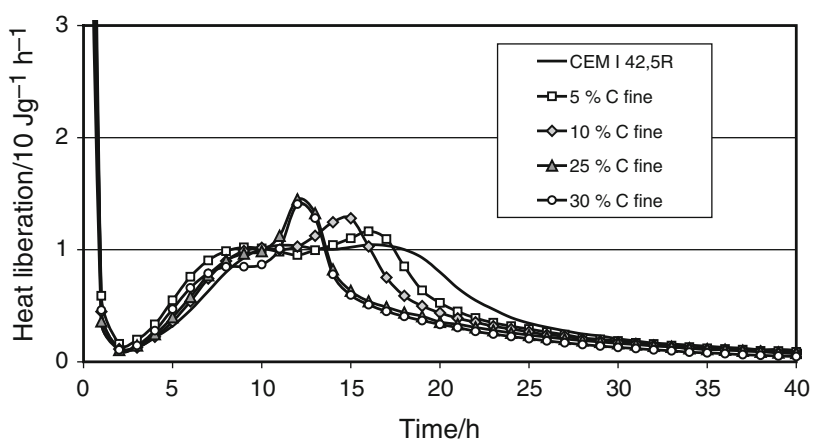

Fig. 2 Heat evolution of cement with fine limestone powder additive

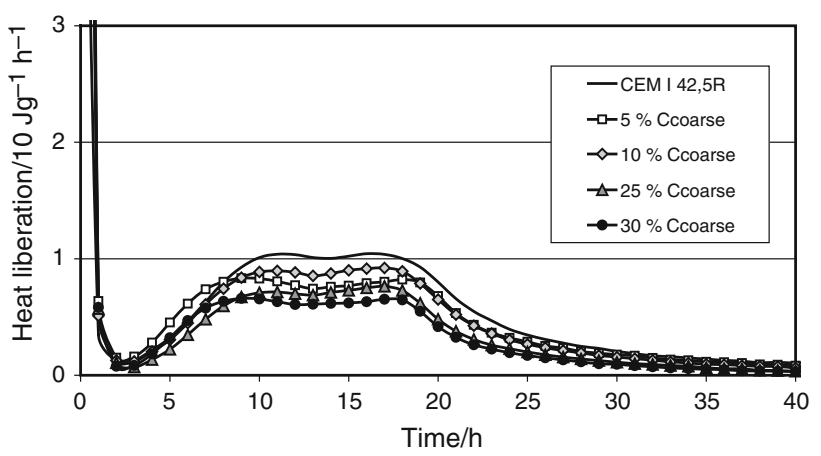

Fig. 3 Heat evolution of cement with coarse limestone powder additive

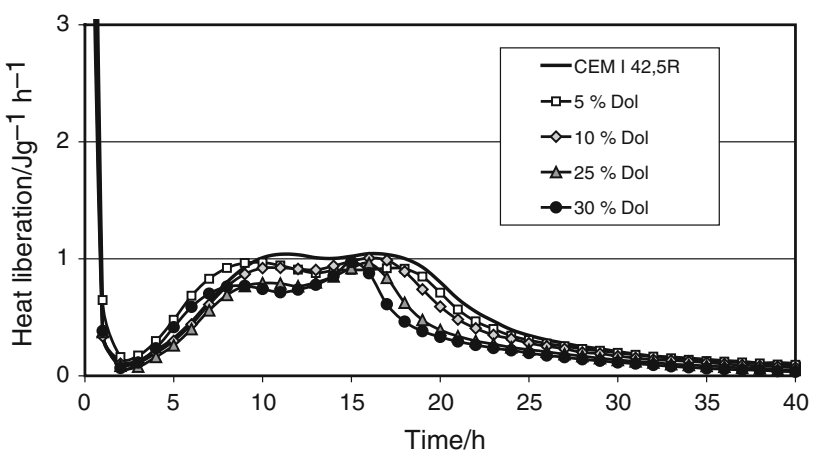

Fig. 4 Heat evolution of cement with dolomite additive

finest limestone powder is more clearly pronounced, in the form of separate, third peak attributed to the calcium aluminate intensive hydration (possible formation of calcium carboaluminate) [14-16]. However, the total heat evolved values do not decline much from those for the other series; dolomite gives similar course of heat evolution as coarse aggregate. The differences do not exceed generally the $5 \%$ of total values.

The conductivity curves reflecting the concentration of ions in the liquid phase are obtained at higher $w / c$ (because of instrumental reasons) to show a competition between dissolution and precipitation from the liquid phase under
Table 2 Heat evolved on hydration

\begin{tabular}{lllr}
\hline Samples & $\begin{array}{l}\text { Heat evolved } \\
\text { value, kJ g after } \\
41 \mathrm{~h} / \text { for } \\
1 \mathrm{~g} \mathrm{mixed} \mathrm{sample}\end{array}$ & $\begin{array}{l}\text { Heat evolved value, } \\
\mathrm{kJ} \mathrm{kg} \text { after } 41 \mathrm{~h} / \mathrm{for}\end{array}$ & $\begin{array}{l}1 \mathrm{~g} \text { cement in } \\
\text { sample }\end{array}$ \\
\hline CEM I & 264 & 264 & \\
$5 \% C_{\text {fine }}$ & 274 & 288 & 100 \\
$10 \% C_{\text {fine }}$ & 258 & 287 & 109 \\
$25 \% C_{\text {fine }}$ & 230 & 307 & 109 \\
$30 \% C_{\text {fine }}$ & 221 & 316 & 116 \\
$5 \% C_{\text {coarse }}$ & 261 & 275 & 120 \\
$10 \% C_{\text {coarse }}$ & 253 & 281 & 104 \\
$25 \% C_{\text {coarse }}$ & 220 & 293 & 106 \\
$30 \% C_{\text {coarse }}$ & 198 & 283 & 111 \\
$5 \% C_{\text {dolomite }}$ & 273 & 287 & 107 \\
$10 \% C_{\text {dolomite }}$ & 232 & 258 & 109 \\
$25 \% C_{\text {dolomite }}$ & 208 & 277 & 107 \\
$30 \% C_{\text {dolomite }}$ & 195 & 279 & 98 \\
\hline
\end{tabular}

$C_{\text {fine }}$ fine limestone powder, $C_{\text {coarse }}$ coarse limestone powder

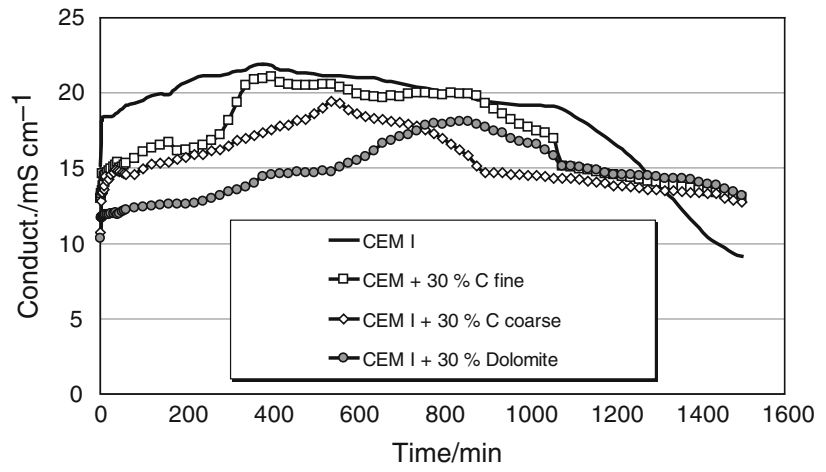

Fig. 5 Conductivity of cement suspensions produced from CEM I 42,5R with additives (Cfine fine limestone powder, Ccoarse coarse limestone powder $)(w / c=10)$

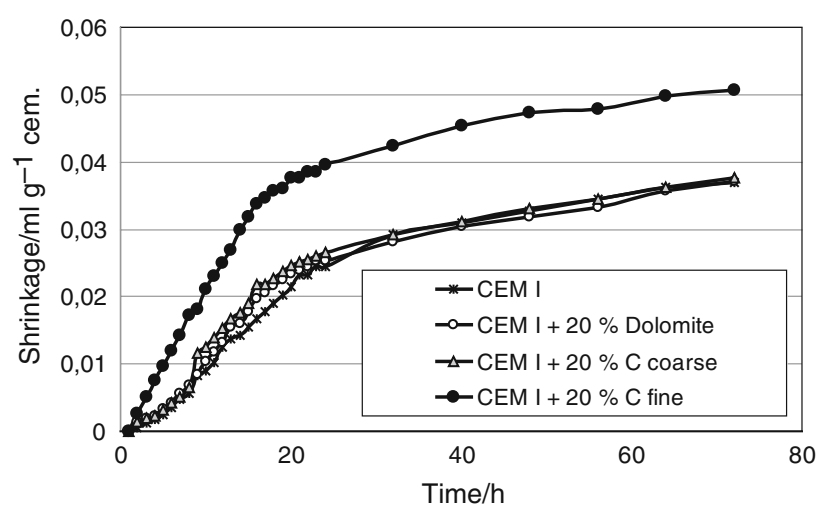

Fig. 6 Chemical shrinkage of pastes produced from CEM I 42,5R with additives (Cfine fine limestone powder, Ccoarse coarse limestone powder) $(w / c=0.4)$ 


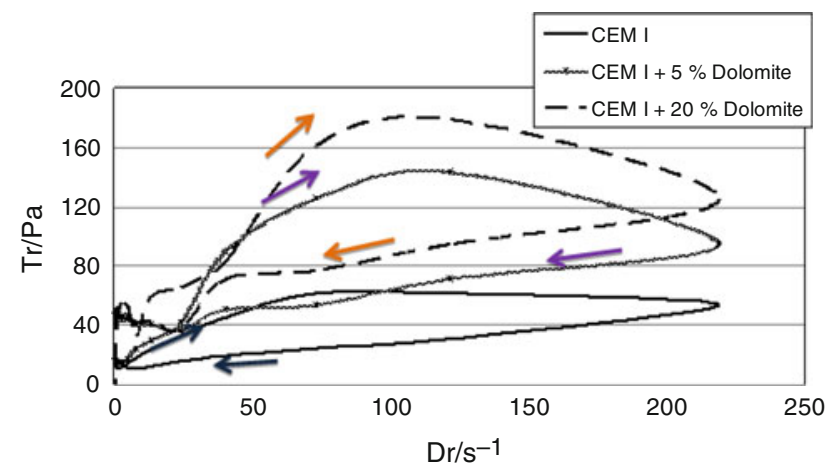

Fig. 7 Flow curves of cement pastes produced from CEM I 42,5R with dolomite

Table 3 Rheological parameters of hydrating cement-dolomite pastes

\begin{tabular}{lcccc}
\hline Samples & $w / c$ & $\eta / \mathrm{Pa} \mathrm{s}$ & $T_{\mathrm{y}} / \mathrm{Pa}$ & $T_{\max } / \mathrm{Pa}$ \\
\hline $\mathrm{CEM} \mathrm{I} 42,5 \mathrm{R}$ & 0.4 & 5.4 & 11.8 & 16.1 \\
$\mathrm{CEM} \mathrm{I}+5 \% \mathrm{CaMg}\left[\mathrm{CO}_{3}\right]_{2}$ & 0.4 & 13.4 & 42.7 & 68.9 \\
$\mathrm{CEM} \mathrm{I}+20 \% \mathrm{CaMg}\left[\mathrm{CO}_{3}\right]_{2}$ & 0.4 & 16.5 & 45.1 & 71.5 \\
\hline
\end{tabular}

$\eta$ viscosity, $T_{\mathrm{y}}$ yield stress, $T_{\max }$ rigidity of thixotropic structure the influence of different factors. The results of conductometric measurements in the suspension with water to solid ratio 10 should be compared to the typical curve for neat cement-after rapid growth soon after mixing with water the conductivity/concentration increases slowly to some maximum (corresponding to supersaturation) and then diminishes because of the precipitation of hydration products. The results for dolomite and limestone during the first minutes are quite similar; however, presumably the precipitation of early product in the diluted suspension with dolomite occurs better. This would prove the effect of dolomite grains surface as effective nucleating site. The plots for the suspensions with additives show that the conductivity/concentration of ions decreases at early age and subsequently increases slowly to the maximum as well. One could speculate that the deposits of hydration products form on the surface of filling agent grains and lower the concentration; therefore, the maxima of conductivity/concentration in the suspensions with $30 \%$ dolomite and coarse limestone are more or less delayed, while in the fine limestone powder mixture with cement the maximum effect is observed at the same time as in cement suspension.
Fig. 8 SEM. Microstructure of cement-dolomite paste at $w / c=0.5$. Seven-day hydration (a) with EDS plots. See the portlandite crystal $(1, \mathbf{b})$ and spherical aggregate of thin C-S-H plates with $\mathrm{Mg}$ and $\mathrm{Al}(2, \mathbf{c})$

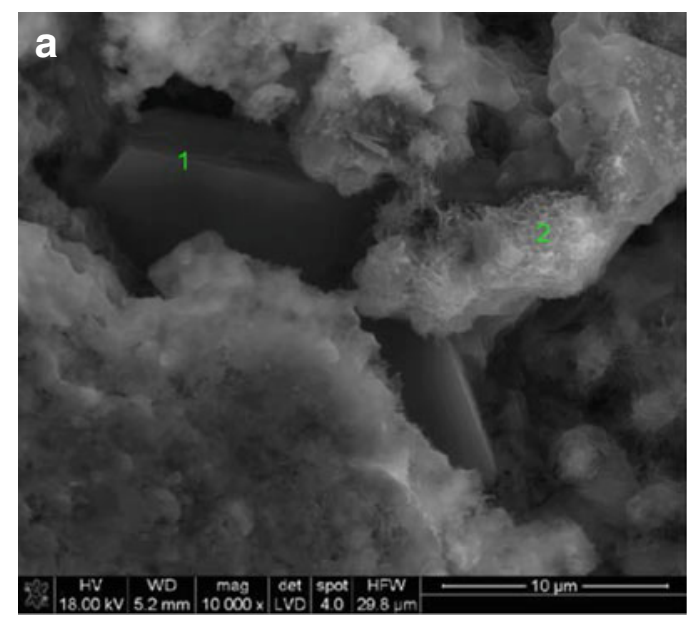

b

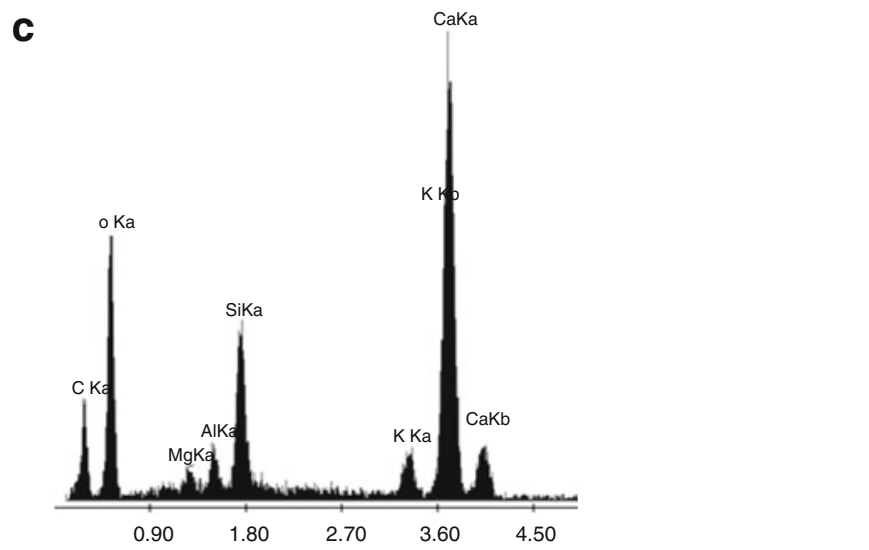


At early age, up to $20 \mathrm{~h}$, a significant increase of chemical shrinkage is observed (Fig. 6). The shrinkage is the highest in the case of paste with $30 \%$ fine limestone powder; it means that the process is accelerated. The shrinkage changes for the other samples occur at first identically as for the reference; the similar rate of water consumption is thus proved. The breakdown of shrinkage curves after the initial growth can be attributed to the increasing role of diffusion mechanism in the hydration process. Since the results of chemical shrinkage measurements reflect the formation of products rich in water and the formation of specific, more or less open pore structure it seems that in this case these factors give the similar results for $20 \%$ coarse limestone and dolomite, as well as for cement paste produced at $w / c-0.4$ but the water consumption is the highest in the case of fine limestone fraction (in this case the possible formation of carboaluminate occurs).

One can notice (Fig. 7; Table 3) that the pastes produced from cement with dolomite filler show the modification of rheological properties and consequently the flow curves; this should be related to the action of additive. A significant increase of the yield stress and plastic viscosity, as a result of introducing the carbonate filler is clearly visible. The broader and broader hysteresis loop proves the strong thixotropy of suspension with dolomite. It means that in the presence of this additive, presumably together with some early hydration products, the strong structure of fluid is produced. This maybe due to the rough surface of filler grains. The thixotropic structure characterized by the so-called rigidity parameter $\left(T_{\max }\right)$ is then strengthen too.

As one could observe under the scanning electron microscope the surface of carbonate small grains was covered with $\mathrm{C}-\mathrm{S}-\mathrm{H}$ formed as a dominating hydration product; this was proved by the presence of $\mathrm{Mg}$ peak on EDS plot (see Fig. 8-the depth of surface penetration by electron beam is ca. $3 \mu \mathrm{m}$ ).

\section{Conclusions}

- The rate of heat evolution accompanying cement paste hydration, total heat evolved, conductivity of hydrating suspension and rheological (flow) properties versus time are modified by carbonate additives. This is due to the nucleating and structural effect of limestone or dolomite filler.

- The very fine carbonate additive (limestone powder of Blaine specific surface $14,500 \mathrm{~cm}^{2} \mathrm{~g}^{-1}$ ), acting as precursor of hydration products (nucleating agents) at early age, contributes much to the formation of hydrated product-the rapid consumption of water (chemical shrinkage measurements) and an additional peak on the calorimetric curve seem to prove the formation of calcium aluminate hydrate phase.

- The changes of chemical shrinkage in case of cementcoarse limestone or cement-dolomite pastes at early age are generally similar to those for the reference cement paste as it is proved by the chemical shrinkage measurements and reflect the supplementary character of this additive.

- The usage of dolomite (dolomitic limestone) as Portland cement clinker replacement should be considered in terms of the potential consolidation properties.

- The densification of cement-dolomite suspension, found during the rheological examinations, seems to point out the usage of dolomite enriched cement material in some geotechnical applications.

Acknowledgements Financial support from the Polish Ministry of Science and Higher Education (tutorial activity of the University of Science and Technology, Faculty of Material Science and Ceramics; Grant No: 11.11.160.938) is acknowledged.

Open Access This article is distributed under the terms of the Creative Commons Attribution License which permits any use, distribution, and reproduction in any medium, provided the original author(s) and the source are credited.

\section{References}

1. Pacewska B, Nowacka M, Wilińska I, Kubissa W, Antonovich V. Studies on the influence of spent FCC catalyst on hydration of calcium aluminate cements at ambient temperature. J Therm Anal Calorim. 2011;105:129-40.

2. Talero R, Rahhal V. Calorimetric comparison of Portland cements containing silica fume and metakaolin. Is silica fume, like metakaolin, characterized by pozzolanic activity that is more specific than generic? J Therm Anal Calorim. 2009;96:383-93.

3. Antonovich V, Aleknevich M, Keriene J, Pundiene I, Stonys R. Investigating the hydration of deflocculated calcium aluminate cement-based binder with catalyst waste. J Therm Anal Calorim. 2012;109:537-44.

4. Nocuń-Wczelik W, Bochenek A, Migdał M. Calorimetry and other methods in the studies of expansive cement hydrating mixtures. J Therm Anal Calorim. 2012;109:529-35.

5. Lothenbach B, Le Saout G, Gallucci E, Scrivener K. Influence of limestone on the hydration of Portland cements. Cem Concr Res. 2008;38(6):848-60.

6. Schöne S, Dienemann W, Wagner E. Portland dolomite cement as alternative to Portland limestone cement. In: Proceedings of the 13th international congress on the chemistry of cements, Madrid, 2011.

7. Nocuń-Wczelik W, Łój G. Effect of finely dispersed limestone additives of different origin on cement hydration kinetics and cement hardening. In: Proceedings of the 13th international congress on the chemistry of cements, Madrid, 2011; abstract 235; CD.

8. Schöne S, Dienemann W, Wagner E. Portland dolomite cement as alternative to Portland limestone cement. In: Proceedings of the 13th international congress on the chemistry of cements, Madrid, 2011; abstract 44; CD. 
9. Zając M, Dienemann W, Bolte G. Comparative experimental and virtual investigations of the influence of calcium and magnesium carbonate on reacting cement. In: Proceedings of the 13th international congress on the chemistry of cements, Madrid, 2011; abstract 264; CD.

10. Garcia E, Alfonso P, Labrador M, Gali S. Dedolomitization in different alkaline media: application to Portland cement paste. Cem Concr Res. 2002;33(9):1443-8.

11. Kurdowski W. Chemistry of cement and concrete. Warsaw: PWN/Polski Cement Editor; 2001. (in Polish).

12. Bouasker M, et al. Chemical shrinkage of cement pastes and mortars at very early age: effect of limestone filler and granular inclusions. Cem Concr Compos. 2008;30:13-22.
13. Lura P, Winnefeld F, Klemm S. A method for simultaneous measurements of heat of hydration and chemical shrinkage on hardening cement pastes. J Therm Anal Calorim. 2010;101:925-32.

14. Taylor HFW. Cement chemistry. 2nd ed. London: Thomas Telford; 1997.

15. Feldman RF, Ramachandran VS, Sereda PJ. Influence of $\mathrm{CaCO}_{3}$ on the hydration of $3 \mathrm{CaO} \cdot \mathrm{Al}_{2} \mathrm{O}_{3}$. J Am Ceram Soc. 1965;48(1): $25-30$.

16. Bonavetti VL, Rahhal VF, Irassar EF. Studies on the carboaluminate formation in limestone filler-blended cements. Cem Concr Res. 2001;31:853-59. 